with the hospital's purpose, each person appreciates his own role better, errors and omissions can be identified and corrected and better working procedures introduced.

In-patient suicides are fortunately rare. Their irregularity of appearance suggests that they may quite often be the consequence of some lapse in the proper working of a ward or unit. Therefore it is worth examining the detailed circumstances of every such death to see whether the ward and hospital have functioned perfectly. Correctible imperfections may be revealed, and staff morale enhanced, in which case the death will have brought a gain.

\title{
Identifying Out-Patients and Ex-Patients Who Have Died Suddenly
}

\author{
Euzabeth KIng, Research Assistant, Department of Psychiatry, University of Southampton
}

In a study to investigate how many ex-patients died since 1974 from sudden or violent causes among all the residents in the catchment area of a general hospital psychiatric unit, the identification of the ex-patients was completed with minimum use of the local coroner as a source of names. Since much of the information available from coroners is available elsewhere, and in view of the considerable pressure of work on coroners, it was felt that alternative sources of information should initially be explored. Three alternative sources, available from death registration procedures, are described and the usefulness of the data available from each source discussed.

By law, every death occurring in England or Wales, and its cause, must be registered in the District in which it occurred, and statutory regulations prescribe what details must be recorded at the time of registration. These particulars, together with the cause of death as stated by the doctor certifying death, or by the coroner to whom the death was reported, are recorded on a Draft entry form (Form 310 ) and verified as correct by the person registering the death, usually a relative, who receives one copy and another is made in the Death Register. Form 310 is posted to the Vital Statistics Branch of the Office of Population Censuses and Surveys (OPCS) where the information is coded and stored on magnetic tape (Mortality File). Under the NHS Acts, a photocopy of all the new entries in the Death Register is sent at the end of each week to the Medical Officer of the District Health Authority (DHA) in which the Registration District or Sub-District lies. Community Health Centres also receive photocopies and permission can be obtained to inspect them.

The information recorded at death registration and held by OPCS and DHAs can be obtained in the form of photocopies, and in addition, a printout of the coded information on the Mortality File is available from Regional Health Authorities. The Mortality File contains all the information recorded on the Death Register relating to residents of the Region except the name of the deceased.

\section{The four sources}

1. Coroners' records

Populations for mortality studies into unnatural deaths have usually been identified from coroners' records since all

TABLE I

Information available as a result of death registration procedures

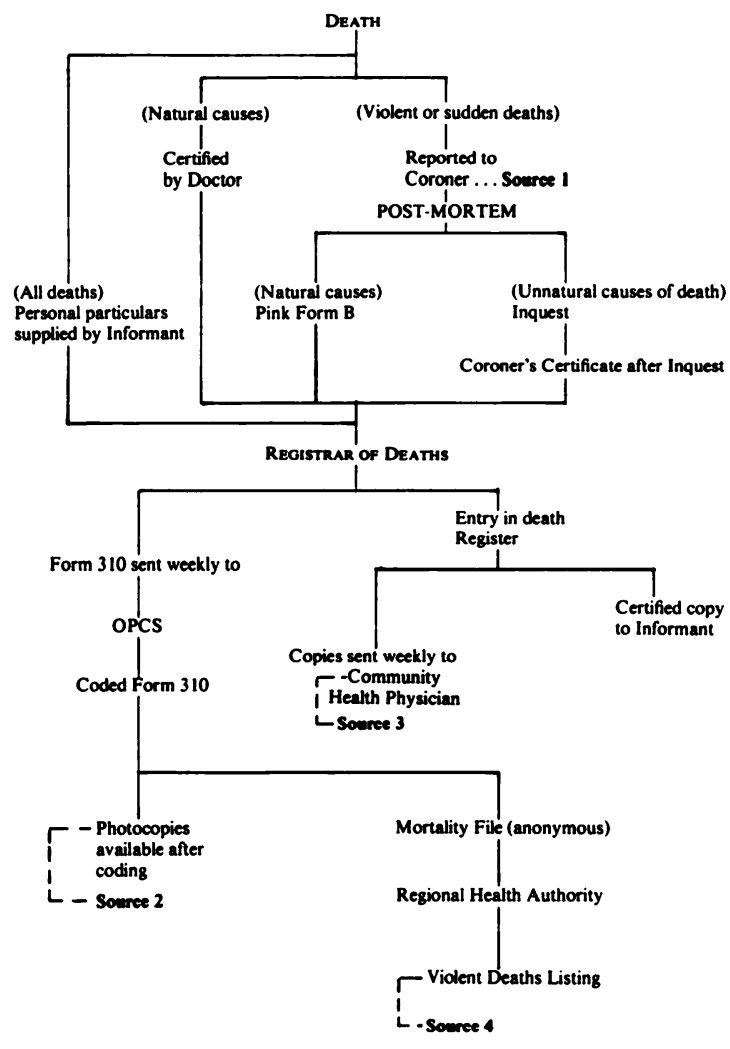


unnatural, violent or sudden deaths of which the cause is unknown must be reported to the coroner in whose jurisdiction the body is found. The coroner therefore has listed information on all who have so died, between 85 per cent and 90 per cent of them being local residents. Of the $10-15$ per cent of persons who die outside the area of their local coroner, we have found that fewer than 4 per cent die outside the immediately neighbouring areas in the jurisdiction of the coroners next door.

At first sight the local coroner, and the coroners of neighbouring jurisdictions, are the obvious persons to approach for a list from which patients can be identified; for recent deaths the coroner is the only source. However, for retrospective studies, co-operation in allowing access to inquest files is much more likely if names of patients have been identified from other sources and specific information not otherwise obtainable is requested about the mental and physical state of the person at the time of the death. Only patients and ex-patients whose death has been reported to the local coroners can be identified from coroners' lists, and usually only the names of those whose death was subject to actual inquest (which form a very small proportion of total reported deaths).

\section{Photocopies of Draft entry forms (310)}

The most direct way of obtaining all the relevant information is to purchase photocopies of the Draft entry forms of all relevant deaths from OPCS. However, a fee is charged to generate the list of names of all those who died at the specified times and places and there is also a charge for each photocopy. This can be expensive if photocopies for a whole population are needed to provide a list for comparison with hospital discharge lists. There is also a delay in the availability of the photocopies since the Forms 310 have to be coded and the information stored on the Mortality File. This is not completed until several months after the end of the preceding year. Mortality Files are available from 1975.

Forms 310 are coded with respect to the cause of death, place of death (actually the place where the death was certified) and the Health District in which the death was registered. The cause of death is designated by an International Classification of Diseases (ICD) code number. The classification is revised every ten years and the current revision, the 9th, has been used from 1979.

Deaths for which the underlying cause was due to injury or poisoning are distinguished by an $\mathrm{E}$ preceding the code number. Since all such deaths are subject to inquest, the coroner's verdict and method of death can be deduced from the code number; all suicides are coded between E950 and E959. The first two digits mean suicide and the third indicates the method. For example, suicide by hanging is coded E953 and suicide by drugs E950. Where the verdict was open, in that the evidence was insufficient to show whether an injury was deliberately or accidentally inflicted, the first two digits are 98 with the third digit indicating the method. Accidental deaths due to poisoning are coded E850-869.

Table II illustrates the alternative codings for deaths because of the changes made in the Suicide and Open Verdict codes between the 8th and 9th revisions of the ICD code, and in the coding of deaths due to accidental poisonings. Care must be taken in specifying which ICD codes are of interest for each year when requesting Draft entry forms (310) because of these coding changes.

To get the most complete list of psychiatric ex-patients, it

TABLE II

International Classification of Diseases, $E$ codes (8th and 9 th revisions)

\begin{tabular}{|c|c|c|c|c|c|c|}
\hline \multirow[b]{3}{*}{ Method of death } & \multicolumn{6}{|c|}{ Coroner's verdict } \\
\hline & \multicolumn{2}{|c|}{ Suicide } & \multicolumn{2}{|c|}{ Open } & \multicolumn{2}{|c|}{ Accident } \\
\hline & 8th & 9th & 8th & 9th & 8th & 9th \\
\hline $\begin{array}{l}\text { Poisoning: solids or } \\
\text { liquids }\end{array}$ & 950 & 950 & 980 & 980 & $850-859$ & $\begin{array}{l}850-858 \\
860-865\end{array}$ \\
\hline $\begin{array}{l}\text { Poisoning: gases in domestic use } \\
\text { Poisoning: Other gases }\end{array}$ & $\begin{array}{l}951 \\
952\end{array}$ & $\begin{array}{l}951 \\
952\end{array}$ & $\begin{array}{l}981 \\
982\end{array}$ & $\begin{array}{l}981 \\
982\end{array}$ & $\begin{array}{l}870-877 \\
860-869\end{array}$ & $\begin{array}{l}867-868 \\
869\end{array}$ \\
\hline $\begin{array}{l}\text { Hanging, strangulation and } \\
\text { suffocation }\end{array}$ & $953\}$ & $953\}$ & $\begin{array}{l}983 \\
988\end{array}$ & $983\}$ & $\overline{913}$ & $\frac{1}{913}$ \\
\hline Submersion (drowning) & 954 & 954 & 984 & 984 & 910 & 910 \\
\hline Choking & - & & & & 911 & 911 \\
\hline Firearms and explosives & 955 & 955 & 985 & 985 & 922 & 922 \\
\hline Cutting and piercing instruments & 956 & 956 & 986 & 986 & 920 & 920 \\
\hline Electrocution & 958 & 958 & 988 & 988 & 925 & 925 \\
\hline Jumping from high place & 957 & 957 & 987 & 987 & - & - \\
\hline Falls & - & & & & $880-887$ & $880-888$ \\
\hline $\begin{array}{l}\text { Other and unspecified means } \\
\text { Late effects }\end{array}$ & $\begin{array}{l}958 \\
959\end{array}$ & $\begin{array}{l}958 \\
959\end{array}$ & $\begin{array}{l}988 \\
989\end{array}$ & $\begin{array}{l}988 \\
989\end{array}$ & $\begin{array}{l}929 \\
940-949\end{array}$ & $\begin{array}{l}866-928 \\
929\end{array}$ \\
\hline
\end{tabular}


is worth asking also for deaths coded E911 (deaths due to choking/inhaled vomit) since these deaths can be associated with alcohol or drug abuse.

The usual address of the deceased is coded by OPCS with a four-digit code (OPCS Area Code) which identifies the local government area at County district level and the NHS area at Health District level. Unfortunately for some who have been living in temporary accommodation, the address recorded is not this one but the informing relative's permanent address which may be outside the catchment area under study.

\section{Photocopies of Death Register entries}

Since copies of all Death Register entries are sent weekly to the District Health Authority, a regular check of these names can provide a more complete list of local deaths since deaths from all causes are recorded. In addition, the DHA also receives photocopies of the Draft entry form (310) from OPCS for all residents of the District whose death has been registered in another District in England or Wales. However, there may be a delay of several months before these nonlocal certificates are received since they are first sent to OPCS for coding. From these photocopies, which are usually retained and can be inspected, it is possible to identify patient deaths since 1974, when Area Health Authorities first received the copies, by comparing the total list of names with hospital records.

\section{Mortality File print-out}

Although the Mortality File print-out available from Regional Health Authorities has no names, it can play a part in the identification of residents of a particular area. For example, if a print-out for a particular health district of all residents dying from injury, poisoning, choking and suicide was requested, it would show the Registration Districts (as a code) in which deaths were registered, together with the Register entry number, all personal particulars and the cause of death (as $\mathrm{E}$ code). This print-out gives the total number of violent deaths together with the ages and sex of the victims. Where a resident's death has been registered in another District, it is possible to identify and contact the coroner in whose jurisdiction that District lies and obtain further information relating to that death.

For local deaths, to get the names the Register entry numbers on the print-out can be compared with the corresponding Register entry numbers on the photocopies held by the DHA of the Death Register entries.

When using the Violent Deaths (all E coded deaths) listing of the Mortality File, it should be borne in mind that not all deaths so classified have been subject to an inquest, although they will have been reported to the Coroner as having a 'violent' element in the cause. For example, deaths of elderly

TABLE III

Comparison of various sources

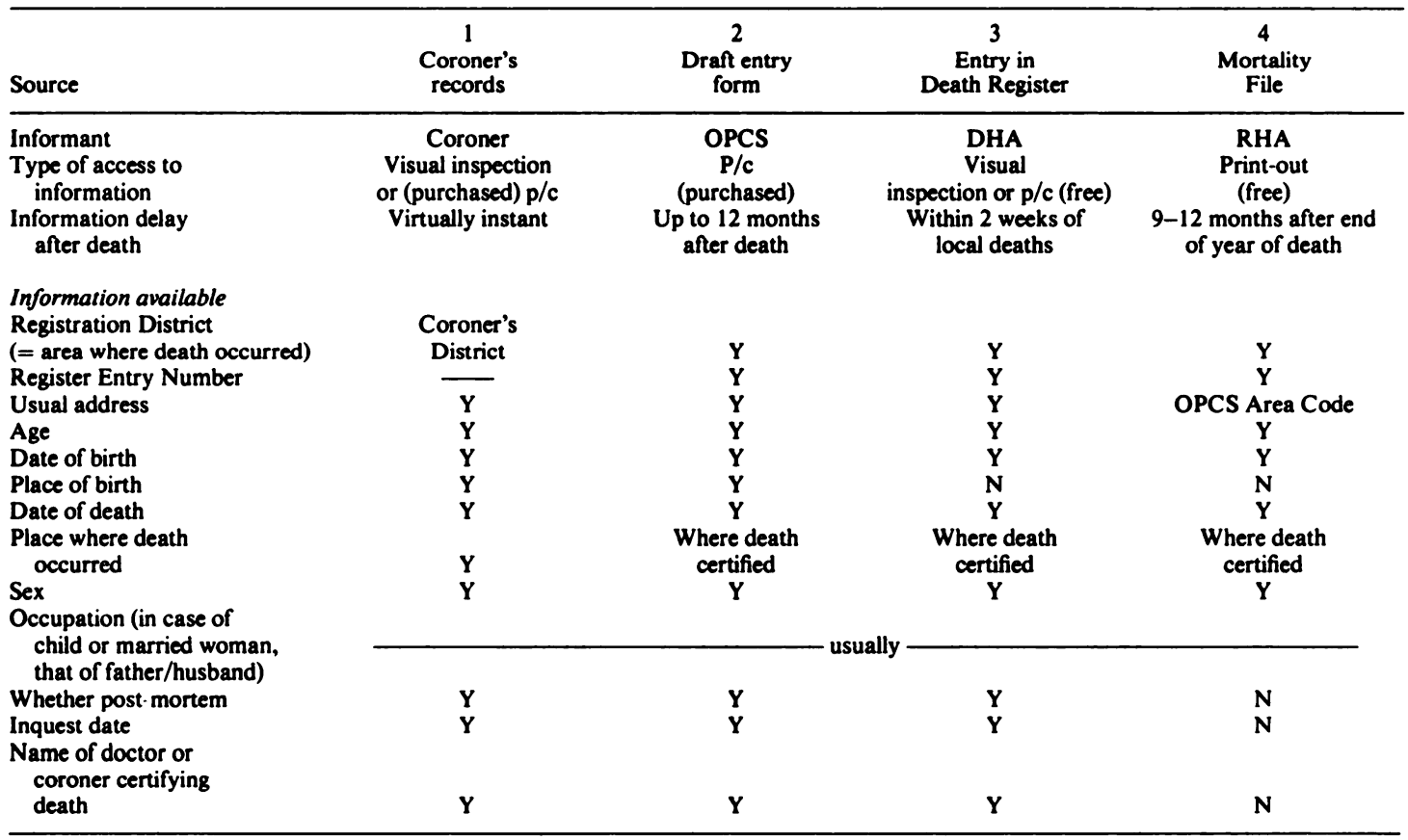

$\mathrm{P} / \mathrm{C}=$ photocopy $; \mathrm{Y}=\mathrm{Yes}-$ information available; $\mathrm{N}=\mathrm{No}$-information not available. 
people from pneumonia consequent upon prolonged bed-rest following a fall resulting in a broken leg are technically 'violent' (coded E880 - fall on or from stairs or steps; E884-fall on same level from slipping, tripping or stumbling) and must be reported. Some coroners do not hold inquests into such deaths unless the fall occurred in a hospital or old people's home.

A further limitation applies to the place of death. This coding is hopelessly unreliable as a source of information on in-patient deaths because:

i. The code indicates the place where death was certifiednot where the event leading to death, or in fact the death itself occurred. (Deaths are not always recorded as 'Dead on arrival at ... Hospital' but often recorded as 'Died in ... Hospital' when resuscitation techniques have been unsuccessfully applied before certifying death);

ii. Deaths in general hospital psychiatric units are designated as 'NHS non-mental' deaths;

iii. In-patients who are transferred from mental hospitals to intensive care units in general hospitals are recorded as 'NHS non-mental' deaths;

iv. Psychiatric or mental hospital in-patients who die after absconding are recorded as dying 'at home' or 'elsewhere'.

Thus it is impossible to assess the number of psychiatric or other in-patient deaths from OPCS statistics on the place of death, and the number classified as 'NHS-mental deaths' must be a minimum.

\section{Conclusion}

It is possible, using information generated by the statutory Death Registration procedure, to identify all persons resident in a particular area who have died from a specific cause of death during a specified period with minimum recourse to coroners' records, and subsequently to determine which of them have been psychiatric patients prior to their death. There are four source points (Table I). Table III gives an inventory of the information available from each source. A list of publications of use in making maximum use of the coded information is as follows:

Report of the Committee on Death Certification and Coroners (Brodrick Report). Cmnd. 4810. HMSO, 1971. Population and Health Statistics in England and Wales. OPCS, 1980.

Area Code for Recording Place of Residence and Place of Birth. OPCS.

Death, Layout of Primary Record, 1973; and Layout of Primary Death Record with Multi-Cause, 1976-78. OPCS via Regional Health Authority.

Topographical Arrangement of Registration Districts and Sub-Districts. OPCS via Regional Health Authority.

\section{The Italian Experiment}

\section{Silvio Benaim, Department of Psychological Medicine, Royal Free Hospital}

In the beginning of the 19th century Italy was in the forefront of psychiatric reform. The question as to whether it was Chiarugi (1759-1820) or Pinel (1745-1826) who was the first to unchain patients in mental hospitals has remained unanswered. With the death of Chiarugi, however, the age of enlightenment, which he had heralded, faded and conditions in Italian hospitals reverted to their former state.

There were no significant changes until 1904 when a Mental Health Act was passed in Parliament, but this was aimed at the protection of Society rather than treatment of the individual. Mental hospitals remained large and provided mainly custodial care: they were inexpensively run and the old provincial administrations were only too ready to admit those who could not cope with life outside hospital and needed asylum.

In the early 1960 s in a University Department of Psychiatry which I visited, patients were still tied to the bed by wrist and ankle straps and, some years later, when I questioned the necessity for the same measures in a large provincial hospital, I was told by the Superintendent that physical restraint was less harmful than chemical restraint in the treatment of disturbed patients! Yet in a purpose-built psychiatric unit of another University Psychiatric Department, a mere hundred miles away from that same hospital, conditions were very different and the Unit compared favourably with some of our own more progressive departments. There was, in other words, a great difference in the quality of care in mental hospitals between regions, depending on the attitude of the provincial administration as well as on that of the psychiatrists working in them. It was generally accepted that hospitals in the Northern half of Italy were much more progressive than those in the South.

In the late sixties there were some 100,000 patients in mental hospitals in Italy. Between 1968 and 1978 marked changes occurred in the attitude of society towards the mentally ill and the man largely responsible for this was Dr 